\title{
ARTICLE
}

\section{Emergency Remote Library Instruction and Tech Tools}

\author{
A Matter of Equity During a Pandemic \\ Kathia Ibacache, Amanda Rybin Koob, and Eric Vance
}

\section{ABSTRACT}

During spring 2020, emergency remote teaching became the norm for hundreds of higher education institutions in the United States due to the COVID-19 pandemic. Librarians were suddenly tasked with moving in-person services and resources online. For librarians with instruction responsibilities, this online mandate meant deciding between synchronous and asynchronous sessions, learning new technologies and tools for active learning, and vetting these same tools for security issues and ADA compliance. In an effort to understand our shared and unique experiences with emergency remote teaching, the authors surveyed 202 academic instruction librarians in order to answer the following questions: (1) What technology tools are academic librarians using to deliver content and engage student participation in emergency remote library sessions during COVID-19? (2) What do instruction librarians perceive as the strengths and weaknesses of these tools? (3) What digital literacy gaps are instruction librarians identifying right now that may prevent access to equitable information literacy instruction online? This study will deliver and discuss findings from the survey as well as make recommendations toward best practices for utilizing technology tools and assessing them for equity and student engagement.

\section{INTRODUCTION}

The worldwide COVID-19 pandemic has had important repercussions for university libraries. All library services, including information literacy instruction, moved online in a matter of days, creating a wave of needs that required immediate response. With the closure of university campuses all around the world, academic libraries encountered an unprecedented test of their adaptation abilities. Although online education has been around for many years, widespread use of the remote classroom may have been unprecedented for many librarians until the spring of 2020. This type of online learning, as Charles Hodges et al. explain, is significantly different from the otherwise established domains of online and distance learning because it is unplanned, rushed, and happening in the midst of a crisis. ${ }^{1}$ As they note, "emergency remote teaching has emerged as a common alternative term" to differentiate from standard online education prior to the pandemic. ${ }^{2}$ The authors recognize the different and sometimes overlapping personal and professional impacts COVID-19 has had on our communities, both inside and outside of the classroom.

Rather than broadly assessing emergency remote teaching, the authors are looking at what Jody Greene, referring to teaching during the COVID-19 pandemic, calls "specific technological tools and flexible teaching practices." ${ }^{3}$ This paper is concerned with issues of equity, student engagement,

Kathia Salomé Ibacache Oliva (kathia.ibacache@colorado.edu) is Romance Languages Librarian, Assistant Professor, University of Colorado Boulder. Amanda Rybin Koob (amanda.rybinkoob@colorado.edu) is Literature and Humanities Librarian, Assistant Professor, University of Colorado Boulder. Eric Vance (eric.vance@colorado.edu) is Associate Professor of Applied Mathematics and Director of LISA (Laboratory for Interdisciplinary Statistical Analysis), University of Colorado Boulder. (C) 2021. 
and technology tools that could be used to facilitate library instruction during emergency remote teaching. The authors seek to answer the following questions: (1) What technology tools are academic librarians using to deliver content and engage student participation in emergency remote library sessions during COVID-19? (2) What do instruction librarians perceive as the strengths and weaknesses of these tools? (3) What digital literacy gaps are instruction librarians identifying since COVID-19 that may prevent equitable access to information literacy instruction online?

\section{LITERATURE REVIEW}

Technology tools facilitated a quick transition online in March 2020, enabling librarians to interact with students despite the move to emergency remote teaching. However, this fast transition and its associated learning curve accentuated issues of student engagement including equity and accessibility. There is a dearth of existing literature on teaching and learning online during times of great societal stress, with some notable exceptions, including a recent piece about university closures and moving to online classes during student-led protests in South Africa from 2015 to 2017. ${ }^{4}$ As such, this literature review considers some of the barriers that contribute to inequitable information access in online learning, as well as digital literacy definitions. Here we consider both ongoing challenges to equitable online access and specific challenges for the current COVID-19 pandemic.

\section{Barriers to Equitable Student Access in Online Learning}

Equity in academic libraries is widely represented in the scholarship through topics including disability, race, class, and salary gaps among librarians. ${ }^{5}$ However, as our ongoing pandemic illustrates, there is a strong need for more literature regarding students' equitable online access to information during times that call for emergency remote teaching.

The issue of equity may be considered in terms of external and internal challenges, which affect students differently. External barriers include low bandwidth and lack of devices. Some researchers advise letting students communicate through chat instead of a webcam, since webcam use increases bandwidth consumption. ${ }^{6}$ Understandably, colleges may need to provide computers and wireless hotspots to students who lack access to computers or to the Internet. ${ }^{7}$ Moreover, a 2018 Pew Fact Tank publication noted that 15 percent of homes with school-age students (6-17 years old) do not have access to high-speed connection, and this digital divide particularly affects teens and their ability to be involved with homework. ${ }^{8}$ Although this data focused on school-age students, these issues probably affected some college students during the pandemic.

Students may also be experiencing internal barriers such as language differences, lack of selfregulation, lack of previous educational experience, and stress, all of which may affect academic performance. For example, one study found that language barriers challenged international students during remote web conferences with librarians. ${ }^{9}$ Another study of international students showed that their academic success relied significantly on a variety of internal characteristics, such as self-regulation. ${ }^{10}$ Additionally, a survey of students taking online courses showed that previous educational experience, including with online learning or within a given discipline, supported completion of those courses. ${ }^{11}$ Moreover, stress is an internal barrier for students that may have external causes and is likely affecting librarians, faculty, and students during COVID-19. Scholars note that stress changes peoples' use of technology, and this stress manifests differently depending on individual identity markers, such as gender and experience. ${ }^{12}$ 


\section{Technology Tools, Digital Literacy, Student Engagement}

In addition to barriers to equitable access, the digital age that has characterized the late 20th and 21st centuries, has prompted the advent of multiple technology tools that may be used in online library sessions, including emergency remote library instruction. These tools are meant to facilitate instruction and engagement, but they require students and instructors to be comfortable with technology. In the case of higher education, this level of comfort involves digital literacy competencies that surpass what is known as traditional textual literacy.

The American Library Association's (ALA) Digital Literacy Task Force defines digital literacy as "the ability to use information and communication technologies to find, evaluate, create, and communicate information, requiring both cognitive and technical skills." 13 During the pandemic, the technical and cognitive skills of library instructors and students may be compromised due to stress as well as individual situations and specific environments.

One of the technical challenges for remote library sessions stems from the need for instructors to use tools to achieve flexibility and hybridity. Librarians Steven J. Bell and John Shank, addressing the challenges of new technologies for librarianship, coined the term "blended librarian" in 2004 to denote a librarian who combines traditional skills with those involving knowledge of hardware and software as applied in the teaching and learning process. ${ }^{14}$ The concept of the "blended librarian" may be outdated, but it encompasses the notion that librarians are expected to be comfortable with technology. Again, librarians are now facing the mandate of presenting information literacy and library resources online, navigating between and facilitating the use of multiple technology tools and formats. It is worth considering how well our tools meet this mandate.

Although remote learning may be more amenable to some learners than others, there is consensus on the benefits of using technology for teaching and learning even if a learning curve exists for instructors. For example, researchers examining school support for classroom technology found that teachers supported enhanced technology integration even if it surpassed their own technology skills. ${ }^{15}$

Notwithstanding the benefits perceived by teachers, there are also some drawbacks in the use of technology in the classroom, especially for distance learning. Digital technologies researcher Jesper Aagaard, reporting part of a study on "technological mediation in the classroom" refers to two processes: "outside in," where students use educational technologies to acquire knowledge in the classroom, and "inside out," where students use technology tools to withdraw from the classroom visiting non-related websites. ${ }^{16}$ For instruction librarians, student engagement is paramount; therefore, redirecting students who leave the digital classroom is important, though it can be difficult to know when this occurs.

A number of reasons could explain why students may disengage in a distance learning setting, one of them being the lack of digital literacy. Moreover, the belief that higher education students in the 21st century are technologically savvy may be misleading. Citing Mark Prensky, who originated the terms "digital native" and "digital immigrant," Wan Ng explains that the phrase "digital natives" describes those people born in 1980 and after whose lives have been shaped by technology. ${ }^{17} \mathrm{Ng}$ found that while the students in his study were very comfortable with technologies such as word processor software, YouTube, and Facebook, they were not as comfortable using technologies to create content. ${ }^{18}$ There may be a digital literacy divide between 
knowing and using a technology for social media and using a technology to create online content such as web pages and blogs. Similarly, Ng found that when presented with unfamiliar technology, students spent less time learning the new technology and instead focused on preparation of content. ${ }^{19}$ This finding may be of concern to instruction librarians who use a myriad of tools during emergency remote teaching.

It is important to consider that these digital literacy divides could stem from factors not related to a student's age group. Researchers Ellen Johanna Helsper and Rebecca Envon question the notion that a person may be called a digital native if they were born after 1980 . These authors state that there are variables other than generational differences that could define a person as a digital native, such as gender, education, experience, and interaction with technology. ${ }^{20}$ Therefore, even when people grow up in technological environments, they may not be considered digital natives.

To minimize a gap in equity, lecture design, even for one-time library sessions, offers an opportunity to think of technology tools that could increase students' participation and prompt learning. David Ellis, studying classroom resources to enhance student engagement, notes that Padlet, a Web 2.0 technology, supports interaction and learning. ${ }^{21}$ Seyed Abdollah Shahrokni, reviewing another Web 2.0 technology, Playposit, as a video tool for language instruction, states that it "can support learning in language classrooms" if used in a lecture design that includes relevant questions. ${ }^{22}$

Lecture design applies to all types of settings: in person, flipped, and distance learning. Approaches should be applied consistently to help students become more digitally literate and bridge equity issues where possible. Jurgen Schulte et al., providing examples of "new" librarian roles in a science curriculum, note that digital literacy enables better learning. ${ }^{23}$ In the case of emergency remote teaching, instruction librarians may promote digital literacies through the use of technologies that increase students' engagement and their "outside in" participation in the teaching and learning process. Considering these challenges, the authors seek to identify the strengths and weaknesses of technology tools used by librarians and the digital literacy gaps that may prevent access to equitable library instruction.

\section{METHODS}

\section{Instrument}

The authors used a six-question Qualtrics survey approved by the Institutional Review Board at the University of Colorado Boulder. The survey was open for two weeks, between May 10 and May 24,2020 . It is worth noting that the questions were specific to this timeframe, and some responses indicated that instruction librarians were still finishing up spring semester 2020. The survey received 202 responses. However, the number of responses to each question varied as answers were not required. The data collected were both quantitative and qualitative, reflecting respondents' practices, perceptions, and personal knowledge.

Respondents answered two multiple-choice and four free-text questions. For the multiple-choice questions, participants could choose all the options that applied and enter their own choice as well. The multiple-choice questions gathered data on the technology tools that librarians used to deliver content or to engage with students during COVID-19. These questions distinguished between content delivery platforms (like Zoom) and technology tools used for student engagement (like Padlet). The technology tools included in the multiple-choice questions were chosen based on the authors' knowledge of their potential relevance to instruction librarians. The 
final four qualitative questions collected information about respondents' perceptions of strengths and weaknesses of technology tools, as well as digital literacy gaps identified during COVID-19 and other challenges to equitable instruction. Qualtrics provided a report, which the authors organized in a spreadsheet used to analyze the data and create the figures.

The following survey questions were asked:

1. What content delivery technology have you used to create your distance learning library sessions during COVID-19?

2. What technology tools have you used to enhance student engagement in your distance learning library sessions during COVID-19?

3. What are the strengths of the technology tools you're using right now?

4. What are the weaknesses of the technology tools you're using right now?

5. What digital literacy gaps have you identified in your students since COVID-19 closures? ALA's Digital Literacy Task Force defines digital literacy as "the ability to use information and communication technologies to find, evaluate, create, and communicate information, requiring both cognitive and technical skills."

6. What other challenges exist in your ability to effectively provide equitable information literacy instruction during this time?

Please see appendix A for the complete survey instrument.

\section{Participants}

The survey was distributed through email to five listservs associated with academic libraries and library organizations: The Seminar on the Acquisition of Latin American Library Materials (SALALM) listserv, Information Literacy Instruction Discussion listserv, the Library Instruction Roundtable (LITA) listserv, the LITA Instructional Technologies Interest Group listserv, and the Literature in English discussion list. These organizations were chosen due to their connection with library instruction in academic libraries and the authors' subject specialty affiliations (Romance Languages and English and American Literature).

\section{Grounded Theory Approach}

The data for questions 3, 4, 5, and 6 were analyzed using a basic grounded theory approach, where the authors collected themes and patterns from the responses rather than approaching the data with pre-existing hypotheses. ${ }^{24}$ Based on their observations, the authors categorized responses according to an agreed-upon set of keywords. In addition, after coding the data separately, the researchers examined every answer together to ensure consistency and reliability. A mixedmethods survey with a grounded theory approach to analysis allowed for a larger number of responses than qualitative interviews. The survey format also allowed for quicker solicitation and analysis of data, given the urgency of the topic and the authors' desire to provide recommendations to colleagues in a timely manner.

\section{FINDINGS}

\section{Popularity of Technology Tools}

Figure 1 shows respondent selections from the list of content delivery tools provided by the authors. A large number of respondents used LibGuides as a content delivery tool during COVID 19 , followed closely by the video conferencing tool Zoom. However, although LibGuides and Zoom displayed a substantial amount of concurrence among the respondents, fewer than half of the 
respondents used the rest of the technology tools shown in figure 1. These data suggest that a large number of the respondents were able to deliver library instruction via synchronous learning through Zoom or by providing resources asynchronously via LibGuides, and thus had the opportunity to have at least some engagement with students.

Figure 1 also shows that more respondents used Snagit and Screencast-o-matic to create videos than PlayPosit. Similarly, a little over one-eighth of respondents used the graphic design tool Canva to create content, although this tool had better usage than Adobe Illustrator, which was only used by one respondent. In addition, the communication software Google Hangouts was largely not used by respondents. The authors listed Formative and Pear Deck in the survey options as well, but these were not selected by any respondents (not shown in figure 1).

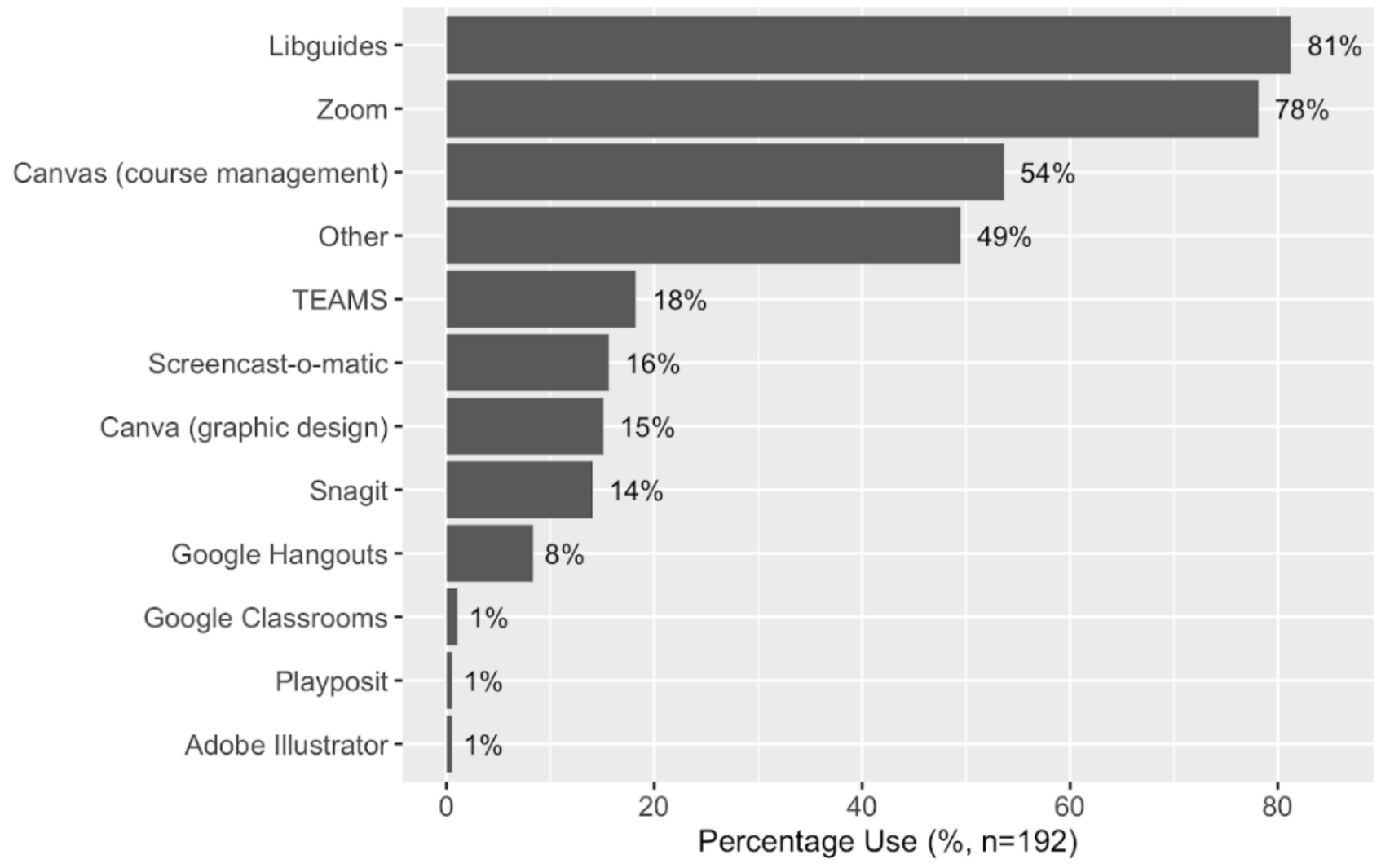

Figure 1. Respondent selections to question 1: What content delivery technology have you used to create your distance learning library sessions during COVID-19?

Figure 2 represents the tools used by the 95 respondents who selected Other and entered additional tools in a free-text box in question 1. Tools mentioned, such as WebEx, Camtasia, Panopto, and Kaltura Capture, were used for video conferencing but to a lesser extent than Zoom. Similarly, only six respondents reported using Narrated PowerPoint. Interestingly these tools were still used by more people than PlayPosit. Respondents mentioned a wide array of other technology tools in the free-text box (see appendix B); however, none of these tools were used individually by more than three respondents. 


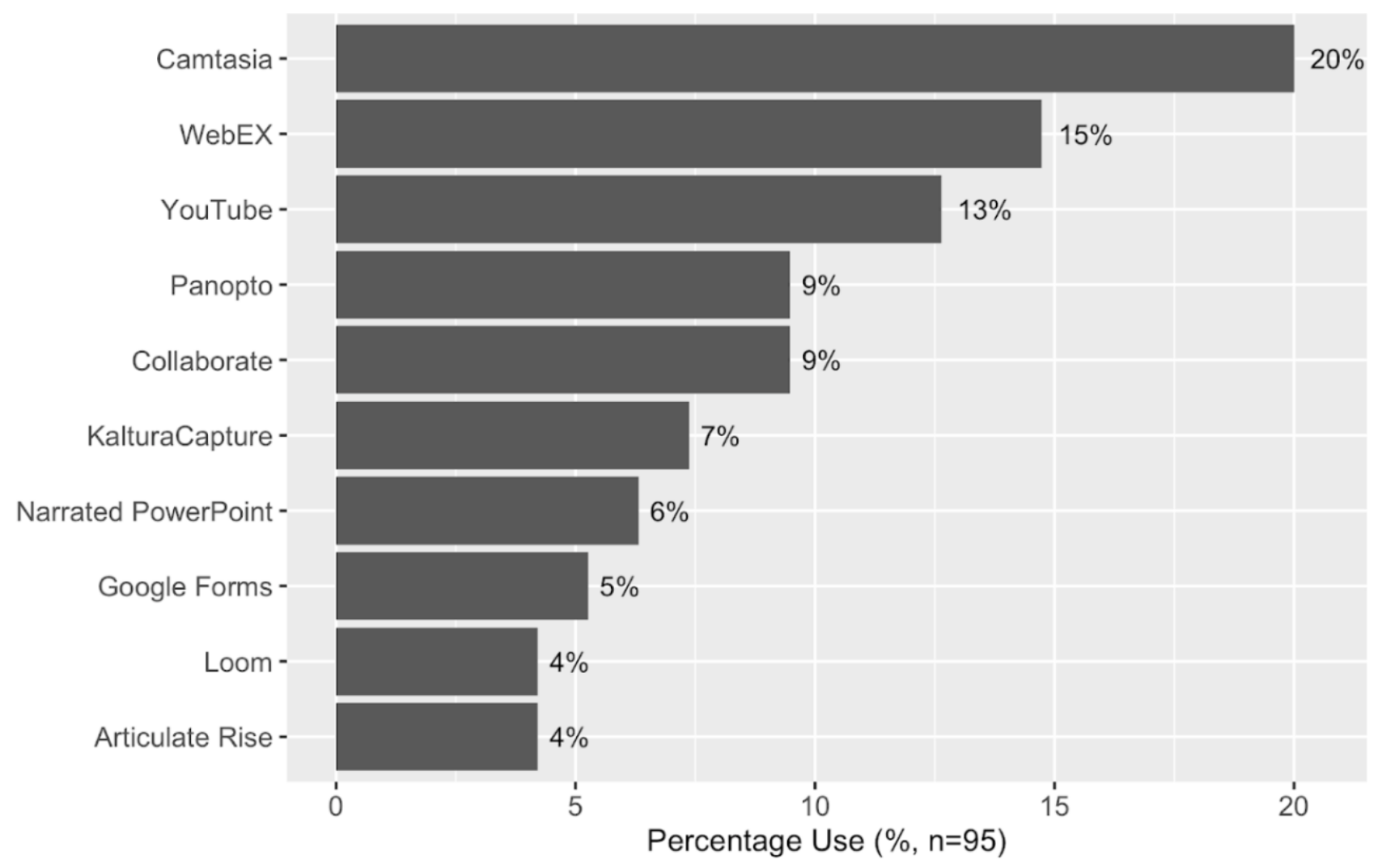

Figure 2. Other content delivery technology used to create distance learning library sessions during COVID-19.

The survey also asked about technology tools used for student engagement in distance learning library sessions during COVID-19. The authors distinguish these tools from content delivery tools, as they are often utilized in conjunction with some of the tools mentioned in figure 1 to facilitate student interaction. Figure 3 shows that, among the tools listed by the authors, respondents preferred the application Google Forms, found in Google Drive and Google Classroom, as more than one-third of respondents indicated they used this application to enhance student engagement. Although representing fewer than half of the respondents, 18 more people selected Google Forms over Poll Everywhere, the tool with the second-best representation.

Moreover, Poll Everywhere and Padlet, two online tools that enable student participation through custom-made polls and post-it boards, were each utilized by about one-fourth of participants. The game-based learning platform Kahoot was used by nearly one-fifth of respondents, and Mentimeter, another interactive platform allowing students to answer multiple-choice and openended questions, was used by 11 respondents. Less than five percent of the respondents used the interactive technology tools Flipgrid, AnswerGarden, Jamboard, Mural, Slido, and Socrative. No respondents indicated they used Pear Deck, Google Drawings, Quizalize, GoSoapBox, and Yo Teach! (not shown in figure 3).

In addition, 42 respondents entered the names of technology tools they used to enhance student engagement in the Other free-text option. Similar to the responses in the free-text answer for question 1, respondents provided a broad list of technology tools. Two of the tools listed displayed a higher number of concurrences: eight respondents mentioned Zoom polls and four mentioned 
Springshare Libwizard. An additional 20 tools were used by just one participant each (see appendix C).

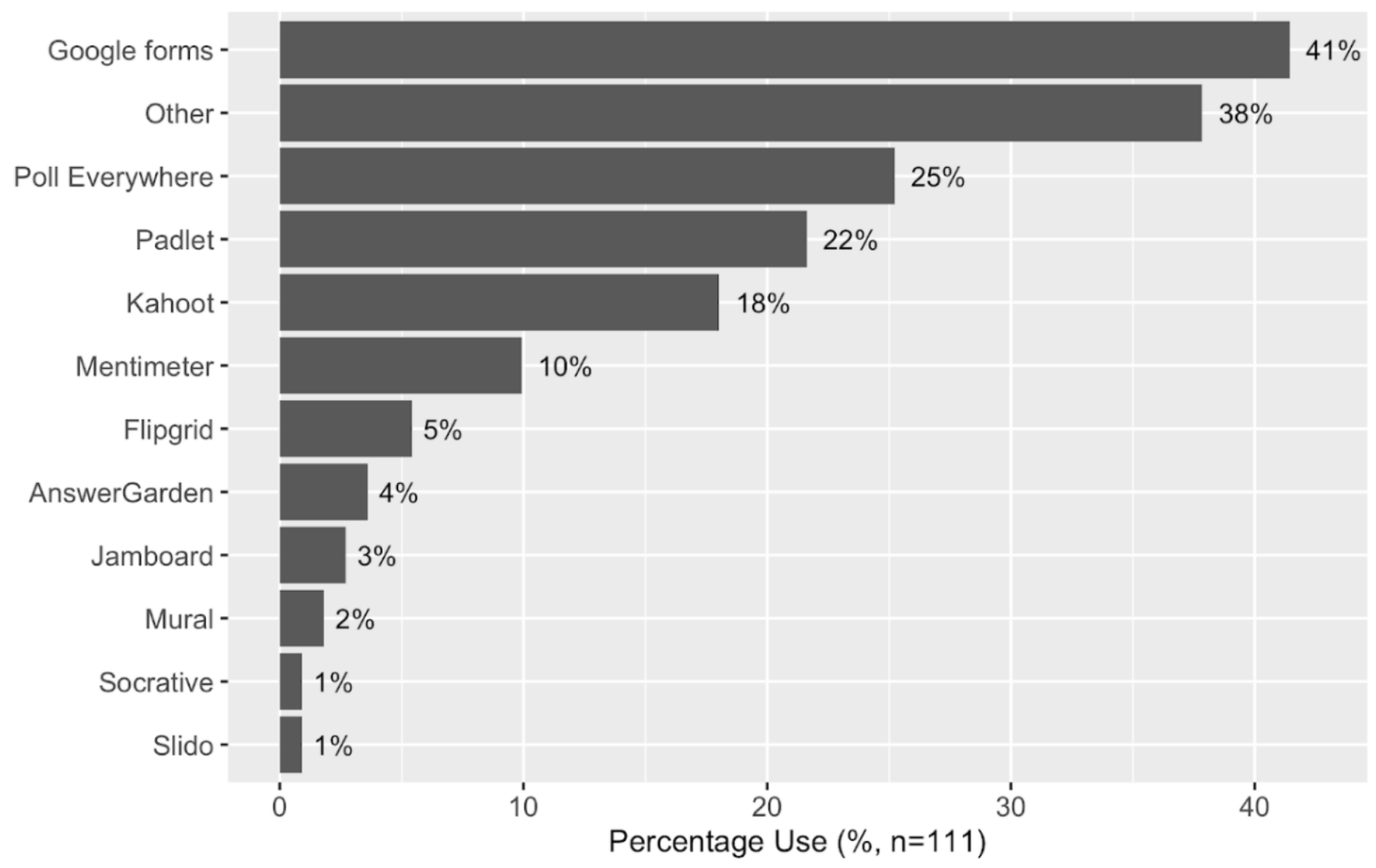

Figure 3. Respondent selections to question 2: What technology tools have you used to enhance student engagement in your distance learning library sessions during COVID-19?

\section{Strengths and Weaknesses of Technology Tools}

Instruction librarians also described the perceived strengths of the technology tools they used. Figure 4 shows that a little less than half of the respondents agreed "easy to use" was an important consideration for technology tools, making it the most frequently mentioned strength. Responses showed interest in ease of use for librarians, students, and faculty alike. For example, respondents included the phrases "our learners were comfortable with them," "it's easy to get started," and "everyone already knows Zoom."

In addition, nearly one-fourth of participants selected the strength "interactive/collaborative" followed at a distance by the strength "flexible," which dropped dramatically to 15 percent. In fact, the number of respondents who noted "interactive/collaborative" was almost quadruple the number of respondents who mentioned the less popular choices "supported by IT" or "captioning functionality." Fewer than 19 participants acknowledged that it was important for the technology tools to enable remote instruction, include recording functionality and screen-sharing functionality, and to be able to enhance communication. Only 11 participants wrote that it was important for the tool to be readily available.

Respondents referred to other strengths not included in figure 4 due to their infrequency. Nonetheless, some of these strengths offer unique insights. For example, four respondents noted 
that they favor free tools. In addition, three respondents stated that it was beneficial to repurpose content created with technology tools. Two respondents mentioned that they preferred tools that do not require download and/or account creation. Another respondent mentioned that mobilefriendly tools were most helpful for engaging students.

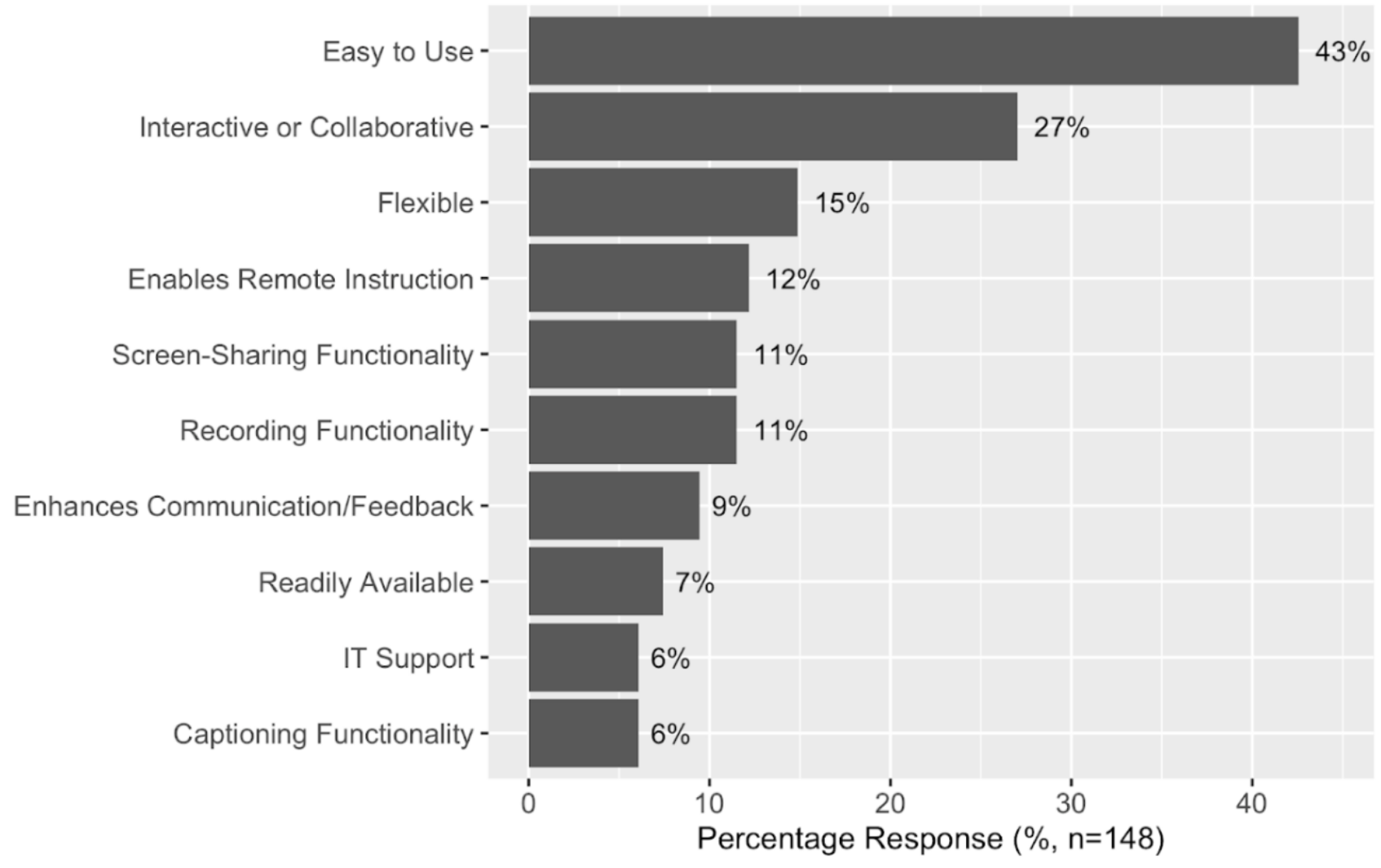

Figure 4. Respondent answers to question 3: What are the strengths of the technology tools you're using right now?

Respondents also shared their observations around technology tool weaknesses. Figure 5 shows that several perceived weaknesses were the inverse of strengths from figure 4, including that tools were "difficult to use" or "not interactive or engaging." Figure 5 also indicates that respondents were divided as to the most significant weaknesses. In fact, not even one-fourth of respondents selected the most frequent response, "not interacting or engaging," displaying a lack of concurrence. The second most-repeated weakness referred to bandwidth requirements, with 27 respondents worrying about the lack of requisite Internet access.

The authors joined together seven weaknesses mentioned by respondents as "other functional limitations." These weaknesses included "lack of screen capture," "connection failures," "lack of captioning," "lack of recording capabilities," "limited sharing screen," "freezing video," and "video quality." Each of these specific limitations was only mentioned a couple of times, but together these functional limitations were mentioned by 17 respondents.

Again, there were some specific weaknesses mentioned by only a few respondents. Some of the highlights included tech overload or too many tools to choose from (two respondents), computer storage requirements (three respondents), and that the tools are not flexible enough or easy to 
integrate into other systems such as Canvas or LibGuides (four respondents). Two people observed that the tech tools they used had no weaknesses.

Interestingly, 18 respondents included keywords and phrases in their answers (not shown in figure 4) that were not directly related to tool weaknesses, but rather described other issues affecting teaching and learning in a remote setting. These included students lacking computers or having only cell phones (seven respondents), students' limited technology skills or attitudes about remote learning (six respondents), students' home setups (three respondents), and limited familiarity with the tools among teaching faculty (two respondents). These kinds of responses illustrate the wide range of interconnected factors impacting librarians' experiences engaging with students and technology during COVID-19.

Finally, 26 percent of librarians answering this question mentioned some weaknesses related to Zoom (not shown in figure 5). To illustrate, some comments included "active learning in zoom [sic] is difficult ..."; "Zoom recordings take up a lot of space and our college is running out of room ..."; "Zoom doesn't work as well when using WIFI [sic], as opposed to connecting through a network"; "it is easy to zone out and not pay attention to zoom [sic]"; "with Zoom it is difficult to interact with students on a one-to-one basis as they breakout [sic] to conduct research"; and "students tend to not have cameras on ... and it's hard to tell if they are actually paying attention." These observations may show that while respondents favor using tools like Zoom, they are also aware of important limitations.

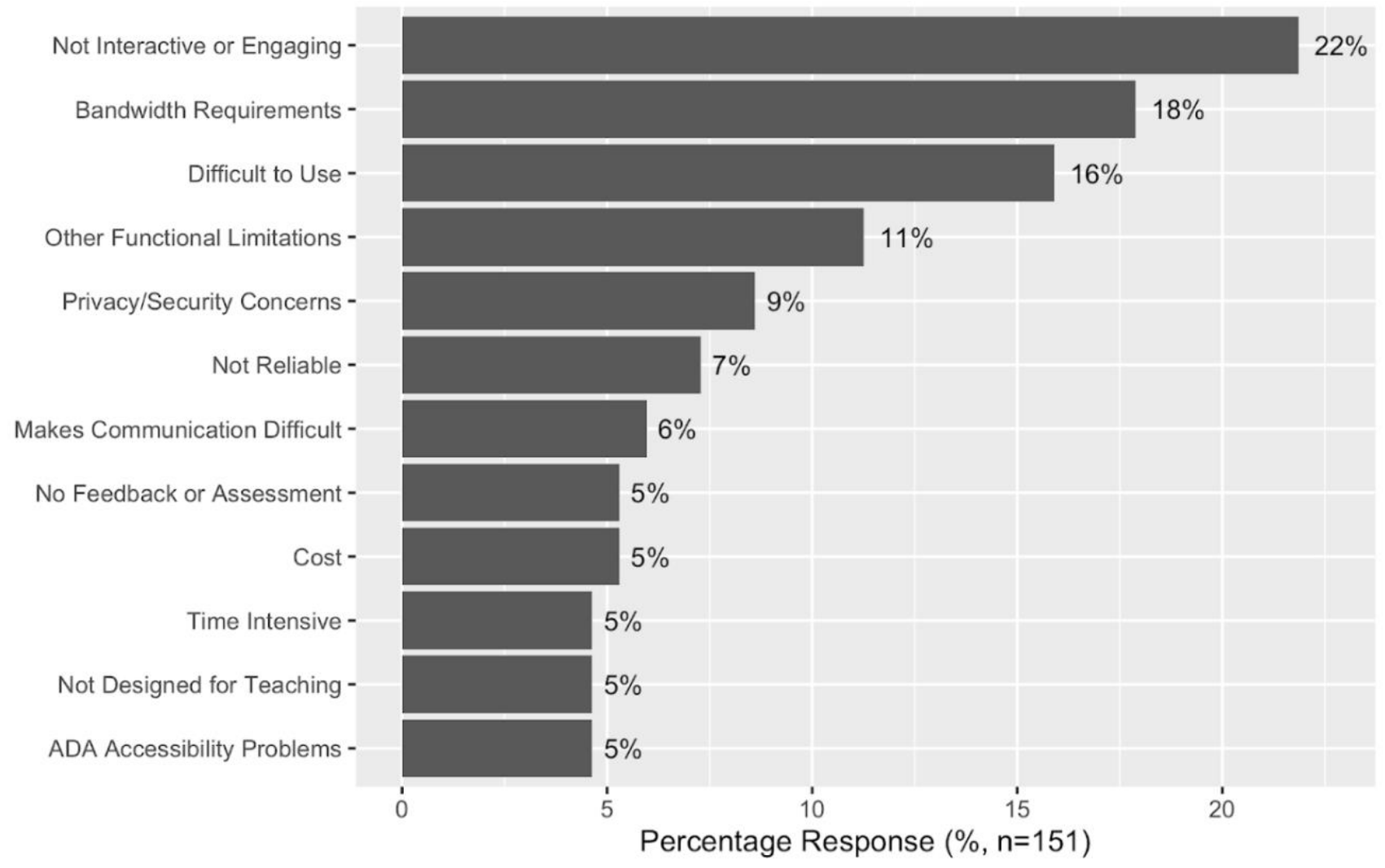

Figure 5. Respondent answers to question 4: What are the weaknesses of the technology tools you're using right now? 


\section{Digital Literacy Gaps}

Beyond describing the technology tools used, respondents were asked to identify digital literacy gaps that they noticed in students during COVID-19 closures. As stated above, the authors defined digital literacy in the survey question according to the ALA Digital Literacy Task Force definition. Still, answers to this question provoked a wide range of responses as seen in figure 6 . The most frequently recurring response was that digital literacy gaps were the same as those perceived before the pandemic, although only 25 respondents agreed on this.

Digital literacy gaps observed by respondents included "lack of tech skills in general," "problems evaluating information online," "ineffective search strategies," "difficulty communicating online," "problems using library resources in general," "problems using online resources," "problems using library databases," and "understanding citation and plagiarism." The second-biggest category, "lack of tech skills in general," included varied responses such as "some of my students lack a basic understanding of ... browsers, upload/download, URL versus link, activate/enable a feature etc."; "students have trouble navigating multiple windows"; and "students are having a hard time trying something new which involves more than a single click or two." Eleven other respondents noted that it was too early to evaluate digital literacy gaps during emergency remote teaching.

One respondent offered insight about the possibility that librarians missed gaps because they were not able to meet with all students. As they stated, "students who have access and are in contact with librarians seem to have adequate skills. I don't know how many students simply lack internet access, and I don't know how many need the library and don't figure out how to access it. ..." Ideas for reaching more students who may not have access to in-class library sessions are mentioned in the Recommendations section below.

When asked about digital literacy gaps, some respondents mentioned student experiences during COVID-19 that were not directly related to digital literacy and therefore are not included in figure 6. However, the authors considered this information relevant because it provided insight into perceived challenges students faced. The authors separated such responses into two groups: external challenges and internal challenges. External challenges mostly involved technology access rather than digital literacy per se, with 22 respondents mentioning lack of tech access as a barrier or gap. It is worth noting that respondents mentioned this lack more than any individual digital literacy gap shown in figure 6. Fifteen respondents also noted that students may lack internet access at home, while five percent mentioned a home environment that was not ideal or conducive to learning. Although these external challenges are not explicitly related to digital literacy, the fact that they are mentioned here may indicate that respondents perceived these challenges as interrelated during the COVID-19 pandemic.

Internal challenges included concepts that may be seen as related to digital literacy but are not explicitly included in the ALA Task Force definition. In fact, many of these challenges had to do with pandemic-specific difficulties such as "emotional issues" arising during COVID-19 (10 respondents). Five respondents worried about information overload, while two respondents each mentioned that students were less likely to ask for help and more likely to have problems following directions during emergency remote learning. 


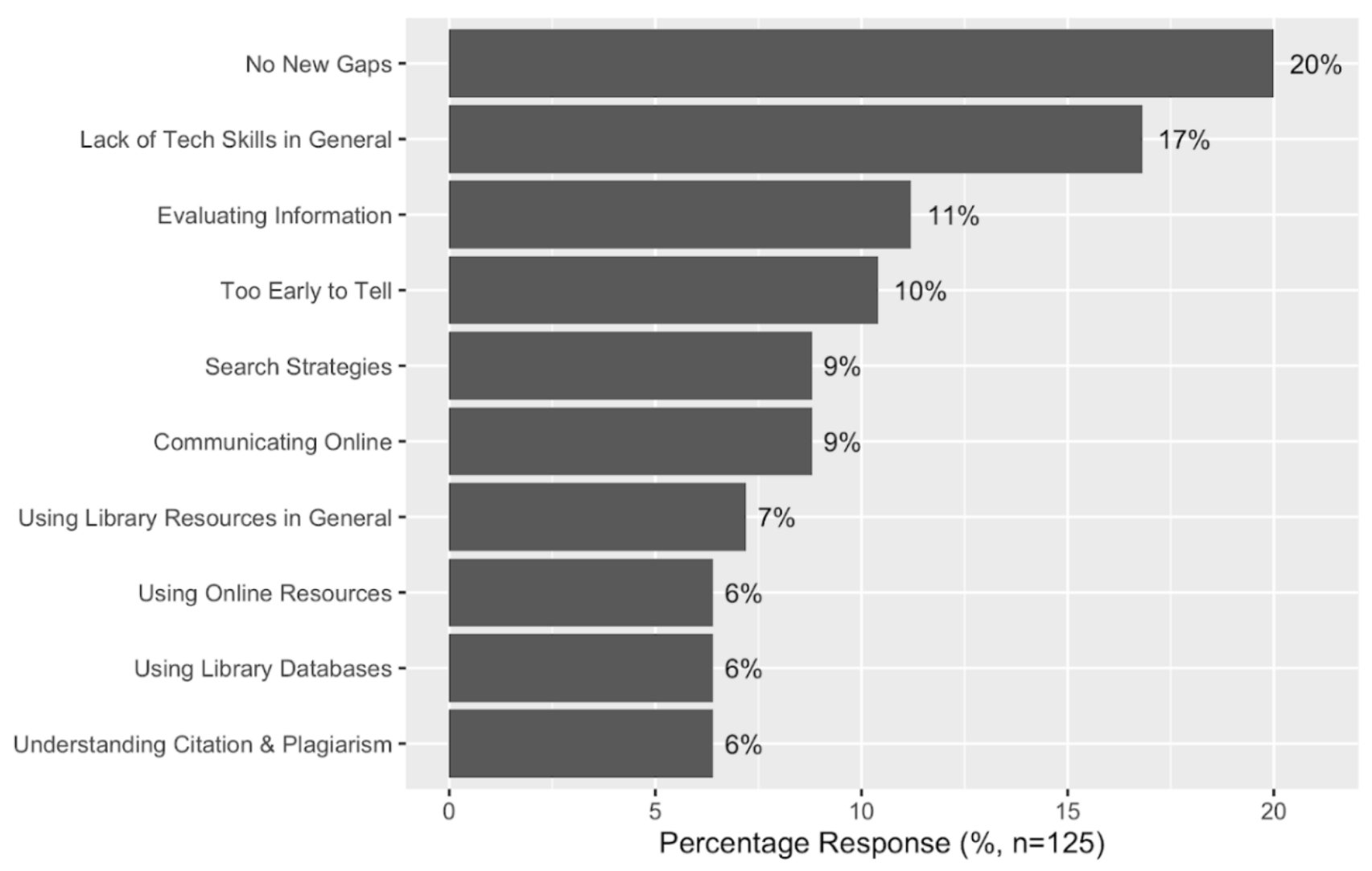

Figure 6. Respondent answers to question 5: What digital literacy gaps have you identified in your students since COVID-19 closures?

The last survey question asked respondents to reflect on any other challenges that may have impacted their ability to effectively provide equitable library instruction during emergency remote learning. Figure 7 displays an array of responses, including some related to technology tools, home environments, and institutional support. Nonetheless, technology access from home was perceived as the most important challenge (39 respondents) followed closely by internet issues ( 35 respondents). For both challenges, the authors included responses that specified lack of tech access for students, teaching faculty, or instruction librarians. Many respondents did not specify who lacked access. However, one could argue that lack of access by any of those three groups may impede connection and student engagement.

Other challenges such as home environment, fewer library instruction sessions, communication barriers with students, lack of student engagement, no time to plan, emotional distress, and issues with synchronous or asynchronous instruction affected 11 percent or less of respondents each. Additionally, the data indicated that librarians perceived more communication barriers with students (14 respondents) than with faculty (nine respondents).

In figure 7, "Asynchronous/Synchronous" refers to problems encountered by respondents that had to do, in general, with the unique challenges of presenting content online either asynchronously or synchronously. For example, respondents mentioned being unsure whether students were engaging with asynchronous content. They also mentioned being asked by faculty to use one format over another, despite librarian preferences. One respondent focused specifically 
on the need for flexibility when addressing equity: "Asynchronous instruction does not allow the real time adaptation to student needs (cognitive and technical)."

Even though figure 7 relates to challenges experienced in providing equitable library instruction, respondents showed that there was also an emotional factor surrounding these challenges. Two revealing responses to the question about challenges included "my kids running around in the background, not having an actual office, being expected to work 40 hours a week while homeschooling and running a household" and "some students [are] more or less in shock from the pandemic; some students have illness in the family; some students have economic issues, some students just don't learn well with online learning only." Other comments stated personal challenges, such as the "stress of living in [the] epicenter of [a] global pandemic" and "my own mental and emotional capacity."

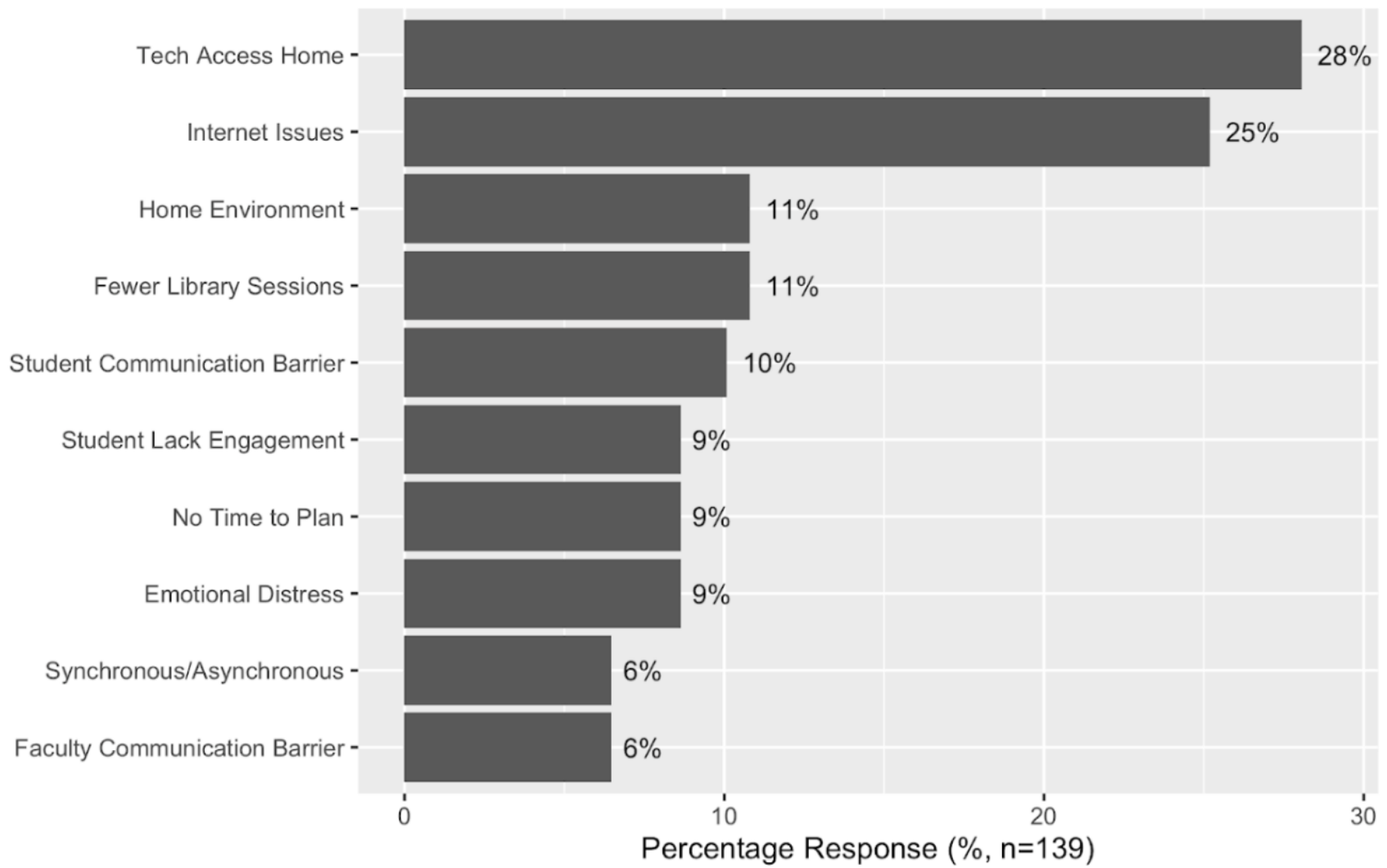

Figure 7. Respondent answers to question 6: What other challenges exist in your ability to effectively provide equitable information literacy instruction during this time?

Because there was often little consensus among responses, the authors created word clouds for all four qualitative questions (figure 8). Each of these questions showed students at the center of instruction librarians' responses, which is not surprising given their roles and the subject of this survey. The purpose of emergency remote teaching and learning is, at its core, to continue to connect students with resources and to engage them in their learning, even and especially when it is challenging to do so. Still, it is meaningful to see students at the heart of these data. 

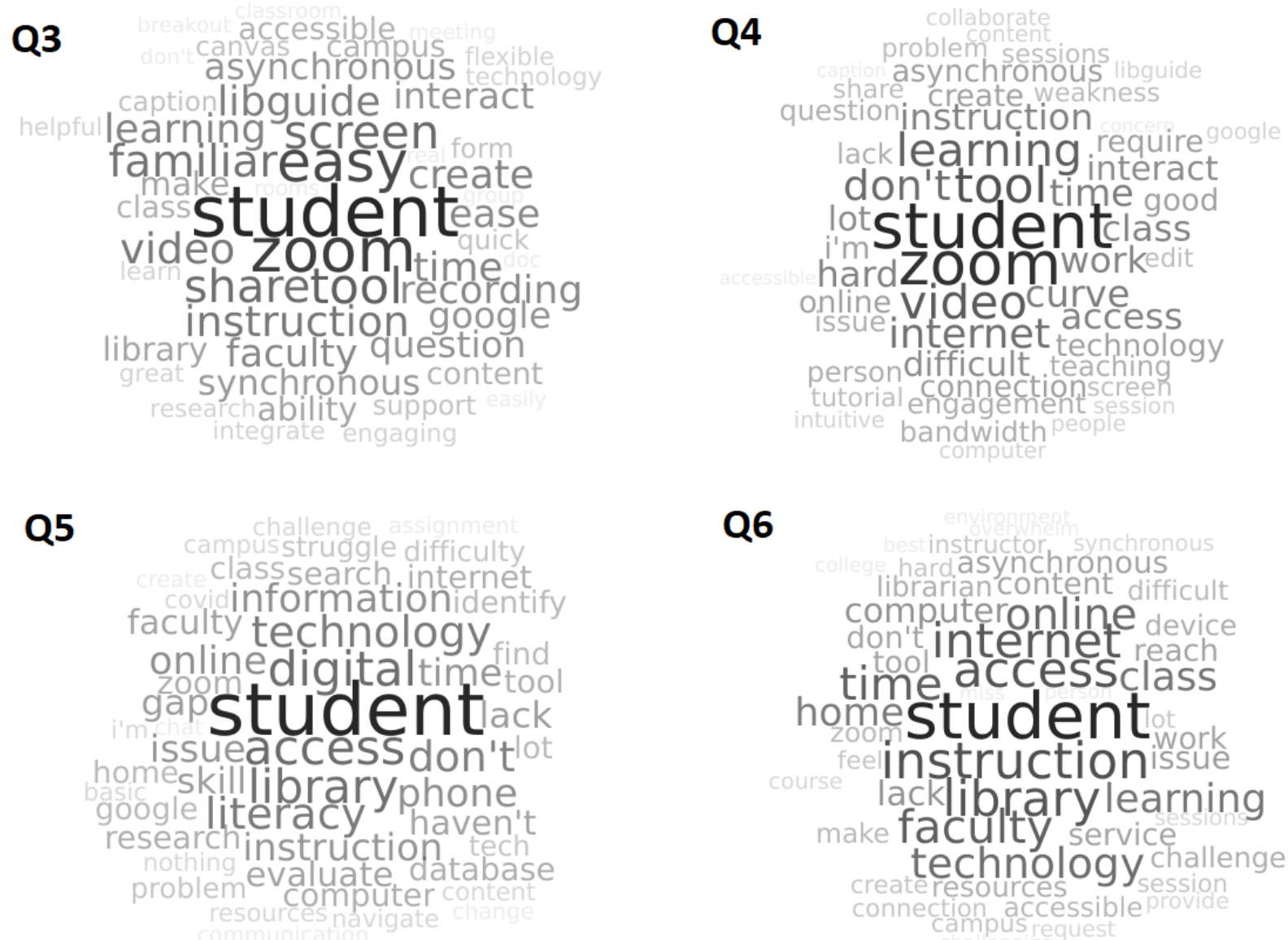

Q6

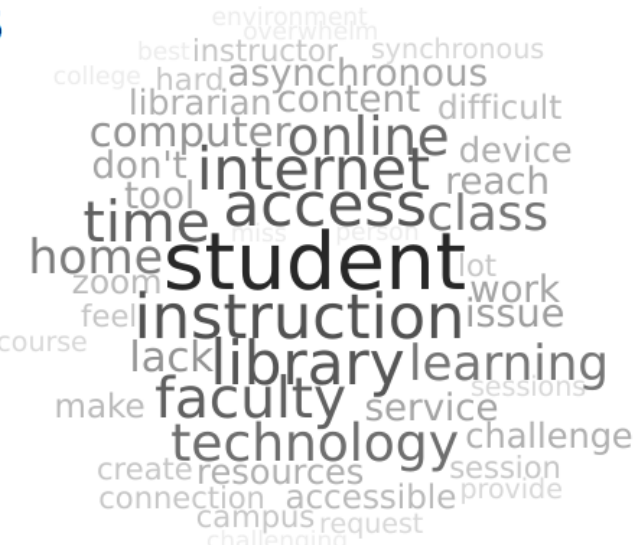

Figure 8. Word cloud visualization for each qualitative question answer set.

\section{CHALLENGES AND LIMITATIONS}

Many of the challenges encountered while analyzing data had to do with creating meaningful keyword codes for the qualitative survey questions. This coding was challenging because respondents expressed varied experiences and opinions and there was no significant consensus regarding tools used, tool weaknesses, digital literacy gaps, or oth er challenges. In contrast, respondents frequently referred to students' lack of technology and internet access, even when the question at hand did not explicitly address this. These challenges speak both to the varied experiences of and institutional responses to COVID-19, as well as perceived lack of tech or internet access among students as a primary barrier to effective emergency remote teaching.

Further, while some questions signaled a clear answer, others required interpretation. To illustrate, respondents used the term "accessibility" inconsistently. Some respondents used this term to refer to accessibility for students with disabilities, and others used it to refer to "availability." Therefore, the authors employed contextual clues to determine meaning. Regardless, if the meaning remained unclear, then these answers were not considered for coding.

Similarly, respondents didn't always use the same language to describe the same concepts. For example, a participant noted that "The technology we have is limited to lecturing and answering questions and providing documents and videos online. We don't have polls enabled ...." The 
authors interpreted this to mean that the technology tools didn't allow for robust engagement with students, though the respondent didn't specifically mention the word "engagement." Again, if context or meaning was unclear, those responses were not coded.

Another challenge occurred in analyzing responses to question 6: What digital literacy gaps have you identified in your students since COVID-19 closure? Some respondents appeared to be unfamiliar with the term "digital literacy," even though a definition was provided within the question. Some respondents referred to hardware access, home environment, tech access, or psychological stress rather than explicitly reflecting on digital literacy gaps as included in ALA's Task Force definition. These responses could indicate either confusion around the definition of digital literacy or, as suggested above, the perception of all these factors being codependent or interrelated.

Limitations of the study included the design of the survey itself. For example, respondents received a list of tools for questions 1 and 2, which may have meant that they were more likely to select these than to remember other tools that they used and add them to the Other category accordingly. Questions 3 through 6, in contrast, did not include any multiple-choice options, which may have limited the thoroughness of responses. For example, the average number of responses to question 3 was 2.08 strengths mentioned per respondent. We think it is likely that respondents would have indicated more strengths had they been presented with a list rather than only a freetext box.

The authors also did not define the difference between content delivery tools and tools for student engagement in the survey. For this reason, there was some overlap noted in the responses for questions 1 and 2. Also, respondents mentioned tools for engagement that were sometimes features of content delivery tools, such as WebEx whiteboards and LMS discussion forums. The vast landscape of tools used meant that our survey could not account for all possible manifestations of technology for content delivery and student engagement.

\section{DISCUSSION}

\section{Questions 1 and 2: Technology Tools Instruction Librarians Are Using to Deliver Content and Engage Students}

The instruction librarians that answered the survey have widely used technology tools such as LibGuides and Zoom in their library seminars during COVID-19. However, as data show, librarians have also used many other technology tools to create and deliver emergency remote library sessions during COVID-19, due perhaps to the wide array of tools available. While LibGuides and Zoom exhibit a high percentage of usage, this result was expected because LibGuides is a wellknown tool used by academic librarians and, according to the company, Zoom became more prominent as a tool during COVID-19. ${ }^{25}$ The relatively low usage of Adobe Illustrator is also somewhat predictable because this tool not only requires a subscription, but also may have a higher learning curve than other free graphic editor and design programs.

Data raised some further questions about the role of Information Technology (IT) departments. Are instruction librarians reaching out to their respective universities' IT departments to learn about technology tools available to them and vice versa? Are IT offices willing and able to provide training via video conferencing if in-person training is not available due to the pandemic? Do IT departments offer enough promotion to advertise these tools? These questions are not addressed in this manuscript but are important avenues for further research. Only six percent of respondents 
recorded "supported by IT" as a strength of the technology tools they were using. This shallow percentage may appear striking but could be understood under the premise that as the pandemic set in across the United States and instruction librarians rushed to prepare and present online sessions, librarians relied on the tools that were most familiar to them instead of learning a new technology tool. The data from this survey would seem to corroborate this, as so many respondents chose "ease of use" as an important strength.

One interesting detail that is worth addressing about the tools is that respondents mentioned Other more than they selected the options the authors provided, which may imply that either the authors did not include the most-used tools or that the number and/or variety of tools is so wide that it is difficult to reach a consensus. One wonders if the tools mentioned in Other had been included as part of the listed options, the number of respondents using these tools would be higher.

\section{Questions 3 and 4: The Strengths and Weaknesses of Tools as They Affect Student Engagement} The authors wanted to know what tools respondents had used to enhance student engagement. Data show that Google Forms is the tool that most of the respondents have used for this purpose. However, fewer respondents used tools that are purposely designed to increase interaction in online sessions, such as Kahoot and Mentimeter, which do not even require a fee for using their basic features.

Respondents' perceptions of the strengths and weaknesses of tools they have used provided useful information. In terms of tools strengthening student engagement, the responses were not as conclusive, as 40 of 150 respondents found these tools interactive or collaborative, and an even lower number of these respondents thought of these tools as flexible or helpful to enable remote instruction. One could argue that ADA capabilities are features that may facilitate student engagement. However, when respondents were asked about the strengths of technology tools they had used, accessibility was not often mentioned as a strength.

Moreover, data showed that only eight respondents referred to ADA problems and three of them voiced concern over captioning capabilities, which is considered a relevant ADA feature. There was no mention of alt text for images, screen-readable and software-neutral file formats, or the importance of user ability to change the color and font setting in their devices to see the content. In fact, only three respondents specifically mentioned issues with videos in terms of their audio quality, lack of auto closed-captioning, and freezing images.

Respondents noted wide-ranging effects of tool weaknesses on both instruction librarians and students. To illustrate, the weaknesses "time intensive," "not designed for teaching," and "no feedback or assessment" likely affected instruction librarians at a personal level as they prepared for and assessed their teaching. In contrast, the weaknesses "ADA problems," "not interactive or engaging," "difficult to use," and "makes communication difficult" might primarily impact students. Other concerns respondents stated that may influence student engagement included poor bandwidth, which affects internet access and causes connection issues. For example, even if librarians try to improve the video quality in Zoom by disabling the higher definition option, or start a session with audio conferencing only, which will decrease the amount of bandwidth needed, students with poor bandwidth may still not be able to engage. Therefore, in situations of emergency remote learning, if students lack bandwidth or an appropriate home environment, learning and engaging may become a challenge. 


\section{Questions 5 and 6: Digital Literacy Gaps and Equitable Instruction}

A number of factors affect the ability to provide equitable library instruction on the librarian side and to engage with equitable library instruction on the students' side. One of these factors is home environment, including access to computers, good bandwidth, or an appropriate working station. Our data specify that 15 respondents perceived "home environment" as a challenge when providing equitable library instruction. In addition, some respondents noticed home environment issues when asked about digital literacy gaps in relation to shared spaces and lack of computers and access.

It's possible that equity issues increased during the COVID-19 shutdown, which raises the question of whether there is a correlation between the issues affecting students, librarians, and faculty. Data showed that of 139 participants, a little over one-fourth of them considered "tech access from home" and "Internet issues" as challenges in the ability to provide equitable library instruction. These challenges, along with "emotional issues," were perceived to affect not only students but also librarians and faculty. Although responses recorded librarians' perceptions on equity issues, often including their own experiences, data revealed that respondents presumed faculty and students were having similar issues.

Data also exhibited that respondents perceived other challenges, such as "fewer library sessions" and "student lack of engagement," that may affect students directly. Fewer library sessions are a challenge that may be further addressed forthwith. However, students' lack of engagement is a difficulty that may require thoughtful outreach, collaboration with mental health offices at the campus level, and reflective and inclusive lecture design.

These challenges may have a negative impact on receiving an equitable learning experience. In fact, less commonly acknowledged gaps may, in some ways, be more important than those frequently mentioned. A well-known gap can be addressed because there is consensus that the gap exists and poses a barrier to equity in education. Unnoticed or overlooked gaps, in contrast, are more difficult to address but may be no less important as barriers to equitable education. Equity issues may also arise as a result of lack of digital literacy skills in students.

Students with higher digital literacy are deemed to perform better in an emergency remote library instruction setting, may be more prone to stay in tune and engaged with the lesson, and have less emotional stress by feeling confident. However, as Wan Ng explains above, those recognized as digital natives may not necessarily have digital literacy, even if they are comfortable with social media tools. ${ }^{26}$ Data do not tell us the age of students; regardless, digital literacy gaps were detected by respondents. These perceived gaps in digital literacies (evaluating information, communicating online, applying search strategies, using library resources and databases, understanding plagiarism and citation, and using online resources) are important for librarians to address during emergency remote learning.

Last, the lack of consensus may be explained by the complexity of the concept of digital literacy. It is possible that many of these gaps existed before, but librarians recognized them as new during emergency remote learning. One response illustrates this idea: "the closure has prompted many more students to request help in every step of the digital literacy process. I'm not sure if students typically ask each other, or their professors/instructors. Regardless, it's exposed that not all students know things I'd assumed they did." Whether these gaps are new or not remains unclear, as evidenced by another respondent who stated, "Nothing new to the COVID era." 


\section{RECOMMENDATIONS}

These recommendations seek to address some of the issues that arose in the data, especially those regarding equity and emergency remote library instruction. To illustrate, one respondent summed up the current situation while also posing a question that appears valuable: "Not all of our students have the same access to stable technology and internet, nor do they all respond to online teaching strategies in the same ways. How do we create equitable and accessible learning opportunities?" While the authors do not have all the answers, based on the analysis of the data and emerging themes, some recommendations may help instruction librarians move forward through the COVID-19 crisis.

\section{Technology and Equity}

The authors realize that a budget is essential for the implementation of recommendations that may reduce both inequitable access to information and lack of digital literacy. Nonetheless, the recommendations below intend to offer guidance on ways to improve equitable access, digital literacy, and student engagement during emergency remote library sessions.

One external digital barrier for students engaging in emergency remote library sessions was the lack of equipment at home, possibly due to economic hardship. University libraries could provide kits containing a Chromebook, webcam, microphone, Wi-Fi hotspot, and headphones to increase equitable access. Access to this equipment may help students feel supported and understood, with a sense of dignity. These offerings should be in coordination with other campus units who may provide similar services, such as Student Affairs and IT departments. Likewise, a coordinated marketing and outreach effort at the campus level may enhance the visibility of equipment available for student use.

As stated above, "ease of use" rose to the top as the most-frequently mentioned technology tool strength, which is understandable given the many stressors educators and students may be experiencing during COVID-19. However, it is important to keep in mind that tools should be "easy to use" not just for librarians and teaching faculty, but especially for students. Nonetheless, given the difficulty of assessing instructional technology and library information literacy sessions right now, it is challenging to know whether students find the technology tools that librarians choose truly "easy to use."

Compounding the perception that tools are easy to use is the possibility that tools may not be ADA accessible. Though the survey did not ask about accessibility explicitly, and while the authors did not vet the tools listed in the survey for their accessibility features, the authors wonder how many tools are fully accessible to all learners. Instead of choosing tools for their perceived ease of use, a further recommendation is to move beyond valuing what's easy to critically reflect on whether tools are fully accessible to students with visual or hearing impairments or learning differences. If the answer is no or unclear, perhaps using basic content delivery tools that are vetted for accessibility features is the better option. It is recommended to follow best practices for using those tools (for example, by referring to guidance from campus IT departments).

If instruction librarians consider themselves "blended," or perhaps even so well-versed in technology that a term like "blended librarian" is no longer needed, they should also prioritize flexible, responsive, and intentional use of technology in their lecture design. If a tool that they assumed would be easy to use for all students is proving challenging for some, librarians should have alternative options and extra support at the ready. They may also ask themselves whether 
use of a technology tool furthers the learning process and outcomes of the course, or if technology is added for its own sake.

In addition, avoiding use of extra tools and technology that does not genuinely enhance lecture goals and priorities may help students avoid stress related to technology, which could further students' emotional well-being during this fraught time. Being clear with students about which tools will be used and for what purpose may help students who would otherwise struggle with layered content delivery and engagement tools. A glossary of these tools, along with when and how they'll be used and links to technical support, could be a helpful support document for students.

\section{Communication and Equity}

It is worth exploring librarian, student, and faculty communication not explicitly focused on technology. Some respondents mentioned outreach and connection challenges that have less to do with technology and more to do with other stressors and limitations. For example, some librarians reported receiving fewer requests for information literacy sessions or library support than usual, and some speculated that this was because of the quick move to emergency remote learning, lack of time to plan, and the possibility that a library session was "extra" and faculty were trying to simplify.

There are several ways to address this challenge. Librarians can attempt to meet students and faculty where they are by offering multimodal learning opportunities, including both synchronous and asynchronous offerings (Zoom meetings, prerecorded videos, tutorials/quizzes, Canvas discussion posts, and LibGuides are a few options). It is also paramount to make sure librarians are reachable at the point-of-need, which may mean extended weekend and evening hours on the virtual Ask-a-Librarian desk. Also imperative is ensuring that virtual services, as well as consultation request links and/or email addresses, are clear and visible to students and faculty on the library's website.

Some survey respondents mentioned that communication with faculty was difficult, and this may have contributed to fewer instruction requests. While it is understandable that faculty may have been less responsive to librarian outreach for a variety of reasons, there are some ways to encourage faculty communications. For example, librarians could provide simple, bulleted lists with updated information on services and offerings, individual attention (focused on specific classes and topics), and options, acknowledging that some faculty will simply not want to share classroom time during emergency remote teaching.

Librarians can also work to bridge the disconnect between IT and their departments by proactively reaching out to learn about best practices not only for technology use, but also for ADA accommodations. Even when information literacy sessions are requested, faculty may not always share student accommodation needs. Librarians can ask for help from IT or other units on campus (such as Centers for Teaching and Learning) to make sure that their communication techniques are aligned with inclusive, user-centered approaches to teaching and learning with technology.

As professionals in a unique role serving both students and faculty, librarians may also check in on a person-to-person basis with both groups. Acknowledging that we are people with mental and physical health needs working together in difficult circumstances is one way of connecting with students and faculty in an authentic way. Emergency remote teaching and learning is different 
from typical remote or online learning and being clear about that might also help everyone adjust expectations and extend compassion.

\section{Professional Development and Personal Support}

While emergency remote teaching and learning may not seem like the best time for professional development, it is important to acknowledge that librarians deserve support in navigating this unprecedented time. Even as we clearly want to help students who may be especially vulnerable during COVID-19, there is a sense of being overwhelmed, and librarians may not always know where to start. While there are online webinars and discussions that provide advice about how to best help students during COVID-19, the authors recommend a more specific approach targeting digital literacy gaps and support systems for librarians.

In reviewing survey responses to perceived digital literacy gaps and other challenges, it became clear that not all librarians are well-versed in digital literacy concepts. If librarians have time to take one approach to professional development as it relates to instruction and information literacy, the authors recommend learning more about digital literacy competencies and thinking critically about how emergency remote library instruction design can address those competencies and potential gaps.

Of course, stresses of the pandemic are impacting librarians as well as faculty and students. It is important that we connect with colleagues and support systems during this time. One option might be to form a community with colleagues to determine best practices for use of technology in instruction among other relevant topics (examples at the authors' library include anti-racist actions and a caregiver's support group). Librarians should also prioritize their own health (mental and physical) and stress management. The recommendations are everywhere but bear repeating: connect with family and friends, exercise, take time away from the computer, and make sure to rest. Librarians should be kind to themselves and their colleagues and offer or ask for support when needed.

\section{CONCLUSION}

As of spring 2021, the COVID-19 pandemic is not yet over. It remains unclear whether and when academic library instruction will return to the old normal. The data collected and analyzed during this paper, as well as the discussion and recommendations, can inform how instruction librarians respond to student needs and challenges as everyone continues to cope with life during emergency remote learning. Especially compelling are the data shared about the strengths and weaknesses of technology tools used to enhance student engagement in library instruction. These data provide parameters that may help other instruction librarians make decisions when choosing a technology tool and be prepared to troubleshoot when issues arise.

A concerning data revealed that digital literacy, as defined by ALA's Digital Literacy Task Force, is a subject that may not be widely understood by instructors. Although our pool of respondents was small, instruction librarians may need a broader understanding of what digital literacies look like in practice when dealing with emergency remote teaching and a diverse stu dent population. While instruction librarians' experiences and perceptions are one important piece of the puzzle, especially in acknowledging shared challenges, it is important to recognize that students may have needs, digital literacy or otherwise, that educators are missing. Though assessment is difficult right now, reflection and attention to the whole student experience is necessary. Working with colleagues on campus to provide technology, including laptop computers and Wi-Fi hotspots, as 
well as evaluating our content delivery and engagement tech tools for ADA accessibility, are examples of ways that instruction librarians can connect students with unmet needs to resources during this difficult time. Examining instruction librarians' ongoing response to the pandemic, while challenging, will help libraries become more emergency-responsive and better able to meet the needs of diverse students in the 21st century.

\section{ACKNOWLEDGEMENT}

We would like to thank Moria Woodruff from the University of Colorado Boulder Writing Center for her help revising this manuscript. 


\section{APPENDIX A: SURVEY INSTRUMENT}

Distance Learning During a Pandemic: A Matter of Equity

We are curious to hear about your experiences of library instruction during the abrupt shift to online learning. In particular, we are researching librarians' use of technology tools for online content delivery and student engagement during COVID-19.This survey should take less than ten minutes to complete. Your answers will be anonymous. Please do not include personally identifiable information. Participation in the survey indicates your consent for us to use the data collected in a forthcoming research paper about using online technology tools to teach information literacy or library seminars during COVID-19. The survey will be open through Sunday, May 24th. Thank you for your participation!

Q1 What content delivery technology have you used to create your distance learning library sessions during COVID-19? Select as many as apply.

Zoom

Microsoft Teams

Libguides

Course Management System (e.g., Canvas)

Formative

Pear Deck

Adobe Illustrator

Snagit

Screencast-o-matic

PlayPosit

Google Hangouts

Google Classrooms

Canva (graphic design tool)

Other 
Q2 What technology tools have you used to enhance student engagement in your distance learning library sessions during COVID-19? Select as many as apply.

Padlet

AnswerGarden

Kahoot!

Mentimeter

Flipgrid

Slido

Socrative

Jamboard

Pear Deck

Mural

Google Drawings

Google Forms

Quizalize

GoSoapBox

Poll Everywhere

Yo Teach!

Other

Q3 What are the strengths of the technology tools you're using right now?

Q4 What are the weaknesses of the technology tools you're using right now? 
Q5 What digital literacy gaps have you identified in your students since COVID-19 closures? ALA's Digital Literacy Task Force defines digital literacy as "the ability to use information and communication technologies to find, evaluate, create, and communicate information, requiring both cognitive and technical skills."

Q6 What other challenges exist in your ability to effectively provide equitable library instruction during this time? 


\section{APPENDIX B: TOOLS MENTIONED BY THREE OR FEWER RESPONDENTS, QUESTION 1, OPTION OTHER}

Ninety-five respondents answered Other to question 1: What content delivery technology have you used to create your synchronous and asynchronous distance learning library sessions during COVID-19?

\begin{tabular}{|c|c|c|}
\hline Tool name & Type of tool & Number of respondents \\
\hline BlueJeans & Online meetings & 3 \\
\hline Google Meet & Online meetings & 3 \\
\hline Jing / TechSmith Capture & Screen capture & 3 \\
\hline Blackboard Ensemble & Video creation & 2 \\
\hline iMovie & Video editing & 2 \\
\hline Guide on the Side & Interactive tutorials & 2 \\
\hline Kapwing & Video and image editing & 2 \\
\hline LibChat & Communications service & 2 \\
\hline Piktochart & Graphics editing & 2 \\
\hline TechSmith Relay & Video creation & 2 \\
\hline ThingLink & Multimedia editing & 2 \\
\hline Adobe InDesign & Desktop publishing & 1 \\
\hline Adobe Photoshop & Graphics editing & 1 \\
\hline Adobe Premiere Pro & Video editing & 1 \\
\hline Amazon Chime & Communications service & 1 \\
\hline Audacity & Audio editing & 1 \\
\hline Chat (in general) & Communications service & 1 \\
\hline Clideo & Video editing & 1 \\
\hline FastStone Capture & Screen capture & 1 \\
\hline Genially & Interactive content creation & 1 \\
\hline Google Sheets & Web-based spreadsheets & 1 \\
\hline GoToMeeting & Online meetings & 1 \\
\hline
\end{tabular}




\begin{tabular}{|l|l|l|}
\hline Tool name & Type of tool & Number of respondents \\
\hline Microsoft Bookings & Scheduling & 1 \\
\hline Microsoft Stream & Video sharing & 1 \\
\hline Powtoons & Video creation & 1 \\
\hline Pressbooks & Content Management & 1 \\
\hline Prezi Video & Video creation & 1 \\
\hline Qualtrics & Surveys & 1 \\
\hline QuickTime & Multimedia editing & 1 \\
\hline ScreenFlow & Video editing and screen capture & 1 \\
\hline Springshare Libwizard & Interactive tutorials and forms & 1 \\
\hline Telephone & Communications service & 1 \\
\hline VideoScribe & Animated video creation & 1 \\
\hline Vimeo & Video sharing & 1 \\
\hline WhatsApp & Communications service & 1 \\
\hline
\end{tabular}




\section{APPENDIX C: TOOLS MENTIONED BY ONE RESPONDENT, QUESTION 2, OPTION OTHER}

Forty-two respondents answered Other to question 2: What technology tools have you used to enhance student engagement in your distance learning library sessions or courses during COVID 19 ? Each tool was used by only one respondent.

\begin{tabular}{|c|c|}
\hline Tool name & Type of tool \\
\hline Articulate Storyline & Interactive e-learning modules \\
\hline Calendly & Scheduling \\
\hline Camtasia & Video editing and screen recording \\
\hline Canva Quizzes & Quizzes \\
\hline Google Voice & Communications service \\
\hline H5P & Programming language for websites \\
\hline \multicolumn{2}{|l|}{ Handout (not a technology tool) } \\
\hline HTML/CSS & Programming language for websites \\
\hline Knight Lab Tools & Storytelling \\
\hline LMS discussion forums & Discussions \\
\hline Microsoft PowerPoint & Presentation platform \\
\hline Microsoft Word & Word processor \\
\hline Nearpod & Interactive lessons \\
\hline Parlay & Discussions \\
\hline Qualtrics & Surveys \\
\hline Remind & Communications service \\
\hline SpeakPipe & Communications service \\
\hline Twine & Storytelling \\
\hline VoiceThread & Video, voice, and text commenting \\
\hline WebEx whiteboard & Drawing tool \\
\hline
\end{tabular}




\section{ENDNOTES}

${ }^{1}$ Charles Hodges et al., "The Difference Between Emergency Remote Teaching and Online Learning," EDUCAUSE Review (2020), https://er.educause.edu/articles/2020/3/thedifference-between-emergency-remote-teaching-and-online-learning.

${ }^{2}$ Hodges et al., "The Difference."

${ }^{3}$ Jody Greene, "How (Not) to Evaluate Teaching During a Pandemic," Chronicle of Higher Education (2020), https://www-chronicle-com.colorado.idm.oclc.org/article/How-Not-to-EvaluateTeaching/248434.

${ }^{4}$ Laura Czerniewicz, "What We Learnt from 'Going Online' During University Shutdowns in South Africa," PhilOnEd (2020), https://philonedtech.com/what-we-learnt-from-going-onlineduring-university-shutdowns-in-south-africa/.

${ }^{5}$ For scholarship on equity and librarianship see Joanne Oud, "Systematic Workplace Barriers for Academic Librarians with Disabilities," College \& Research Libraries 80, no. 2 (2019), https://doi.org/10.5860/crl.80.2.169; Amanda L. Folk, "Reframing Information Literacy as Academic Cultural Capital: A Critical and Equity-Based Foundation for Practice, Assessment, and Scholarship," College \& Research Libraries 80, no. 5 (2019), https://doi.org/10.5860/crl.80.5.658; Scott Seaman, Carol Krismann, and Nancy Carter, "Salary Market Equity at the University of Colorado at Boulder Libraries: A Case Study FollowUp," College \& Research Libraries 64, no. 5 (2003), https://doi.org/10.5860/crl.64.5.390; Freeda Brook, Dave Ellenwood, and Althea Eannace Lazzaro, "In Pursuit of Antiracist Social Justice: Denaturalizing Whiteness in the Academic Library," Library Trends 64, no. 2 (2015), https://doi.org/10.1353/lib.2015.0048; Isabel Gonzalez-Smith, Juleah Swanson, and Azusa Tanaka, "Unpacking Identity: Racial, Ethnic, and Professional Identity and Academic Librarians of Color," in The Librarian Stereotype: Deconstructing Perceptions and Presentations of Information Work, ed. Nicole Pagowsky and Miriam Rigby (Chicago: Association of College and Research Libraries, 2014), 149-73.

${ }^{6}$ Tom Riedel and Paul Betty, "Real Time with the Librarian: Using Web Conferencing Software to Connect to Distance Students," Journal of Library \& Information Services in Distance Learning 7, no. 1-2 (2013): 101, https://doi.org/10.1080/1533290X.2012.705616.

${ }^{7}$ Keith Shaw, “Colleges Expand VPN Capacity, Conferencing to Answer COVID-19," Network World (Online) (2020): 1.

${ }^{8}$ Monica Anderson and Andrew Perrin, “Nearly One-in-Five Teens Can't Always Finish Their Homework Because of the Digital Divide," Pew Research Center Fact Tank News in the Numbers, October 26, 2018, https://www.pewresearch.org/fact-tank/2018/10/26/nearlyone-in-five-teens-cant-always-finish-their-homework-because-of-the-digital-divide/.

${ }^{9}$ Julie Arnold Lietzau and Barbara J. Mann, "Breaking Out of the Asynchronous Box: Suing Web Conferencing in Distance Learning," Journal of Library \& Information Services in Distance Learning 3, no. 3-4 (2009): 113, https://doi.org/10.1080/15332900903375291. 
${ }^{10}$ Aek Phakiti, David Hirsh, and Lindy Woodrow, “It's Not Only English: Effects of Other Individual Factors on English Language Learning and Academic Learning of ESL International Students in Australia," Journal of Research in International Education 12, no. 3 (2013): 248.

11 T. V. Semenova and L. M. Rudakova, "Barriers to Taking Massive Open Online Courses," Russian Education \& Society 58, no. 3 (2016): 242, https://doi.org/10.1080/10609393.2016.1242992.

12 Xinghua Wang, Seng Chee Tan, and Lu Li, “Technostress in University Students' TechnologyEnhanced Learning: An Investigation from Multidimensional Person-Environment Misfit," Computers in Human Behavior 105, (2020): 2, https://doi.org/10.1016/j.chb.2019.106208.

13 “Digital Literacy,” ALA Literacy Clearinghouse, accessed May 16, 2021: https://literacy.ala.org/digital-literacy/.

${ }^{14}$ Steven J. Bell and John Shank, "The Blended Librarian: A Blueprint for Redefining the Teaching and Learning Role of Academic Librarians," College \& Research Libraries News 65, no. 7 (2004): 374, https://doi.org/10.5860/crln.65.7.7297.

15 Vanessa W. Vongkulluksn, Kui Xie, and Margaret A Bowman, “The Role of Value on Teachers' Internalization of External Barriers and Externalization of Personal Beliefs for Classroom Technology Integration," Computer \& Education 118, (2018): 79, https://doi.org/10.1016/i.compedu.2017.11.009.

${ }^{16}$ Jesper Aagaard, "Breaking Down Barriers: The Ambivalent Nature of Technologies in the Classroom, New Media \& Society 19, no. 7 (2017): 1138, https://doi.org/10.1177/1461444816631505.

${ }^{17}$ Wan Ng, “Can We Teach Digital Natives Digital Literacy?" Computers \& Education 59, no. 3 (2012): 1065, https://doi.org/10.1016/i.compedu.2012.04.016.

${ }^{18} \mathrm{Ng}$, “Can We Teach,” 1071-72.

${ }^{19} \mathrm{Ng}$, “Can We Teach,” 1072.

${ }^{20}$ Ellen Helsper and Rebecca Enyon, “Digital Natives: Where Is the Evidence?," British Educational Research Journal 36, no. 3. (2010): 515, https://doi.org/10.1080/01411920902989227.

${ }^{21}$ David Ellis, “Using Padlet to Increase Student Engagement in Lectures," in Proceedings of the 14th European Conference on e-Learning (ECEL 2015), ed. Amanda Jefferies and Marija Cubric (Reading, UK: Academic Conferences and Publishing International Limited): 195.

${ }^{22}$ Seyed Abdollah Shahrokni, "Playposit: Using Interactive Videos in Language Education," Teaching English with Technology 18, no. 1 (2018): 106.

${ }^{23}$ Jurgen Schulte et al., "Shaping the Future of Academic Libraries: Authentic Learning for the Next Generation," College \& Research Libraries 79, no. 5 (2018): 688, https://doi.org/10.5860/crl.79.5.685. 
${ }^{24}$ Chiara Faggiolani, "Perceived Identity: Applying Grounded Theory in Libraries," JLIS.it: Italian Journal of Library and Information Science 2, no. 1 (2011): 4592, https://doi.org/10.4403/jlis.it-4592.

25 “Over 700 Universities and Colleges Now Use Zoom!" Zoom blog, July 15, 2013, https://blog.zoom.us/over-700-universities-and-colleges-now-use-zoom-video-conferencing/.

${ }^{26} \mathrm{Ng}$, “Can We Teach,” 1071-72. 